\title{
DINÂMICA FLUVIAL DO RIO AMAZONAS NO TRECHO ENTRE A ILHA DO CAREIRO E A COSTA DO VARRE VENTO
}

\author{
Aline Gabriela Silveira Araújo \\ Mestranda do Programa de Pós-graduação em Geografia - UFAM \\ Universidade Federal do Amazonas \\ alinegabisa@gmail.com \\ José Alberto Lima de Carvalho \\ Professor Doutor do Programa de Pós-graduação em Geografia - UFAM \\ Universidade Federal do Amazonas \\ albertogeografo@gmail.com
}

\begin{abstract}
RESUMO: O resumo apresenta uma análise da dinâmica fluvial presente no rio Amazonas, entre a llha do Careiro e a Costa do Varre Vento, e como este processo pode vir a comprometer o transporte de grande calado em períodos extremos de vazante. $O$ trabalho é resultado de pesquisas no Mestrado do Programa de Pós-graduação em Geografia da UFAM e objetiva analisar o rio Amazonas, no trecho proposto, no que diz respeito à formação de bancos arenosos e suas implicações ao transporte de grande calado em eventos extremos. Os procedimentos metodológicos iniciaram-se com o levantamento bibliográfico, seguido de análise de imagens de satélites e levantamento batimétrico transversal.
\end{abstract}

Palavras-chave: Dinâmica Fluvial, Vazantes Extremas, rio Amazonas.

\section{INTRODUÇÃO}

Os processos fluviais, caracterizados como erosão, transporte e deposição de sedimentos, fazem parte da dinâmica dos canais fluviais, alternam-se com o decorrer do tempo e do trecho do canal, pois, em alguns trechos é predominante a erosão enquanto em outros a predominância é da sedimentação. No rio Amazonas, o processo não seria diferente do que ocorre em outros canais, no entanto a escala de grandeza e as velocidades dos processos se dão de forma mais intensa e complexa, fato que influencia diretamente no cotidiano dos moradores ribeirinhos.

O trecho proposto para estudo, entre a llha do Careiro e a Costa do Varre Vento, localiza-se à jusante do encontro dos rios Negro e Solimões, que a partir desse encontro recebe o nome de rio Amazonas. No trecho da pesquisa, o rio atua como limite entre 4 municípios do estado do Amazonas, sendo Manaus e Itacoatiara pela margem direita e Careiro da Várzea e Autazes pela margem esquerda.

Apesar de os rios de água branca apresentar a predominância do processo de erosão lateral, regionalmente conhecido como terras caídas, à hipótese levantada é que no trecho a pesquisado, o processo fluvial predominante é o de sedimentação, e que este está alterando as feições geomorfológicas e principalmente a geometria do canal, pois supõem-se que esteja ocorrendo um alargamento do canal em consequência do processo de deposição, seguido da elevação do seu nível de base. 
DINÂMICA FLUVIAL DO RIO AMAZONAS NO TRECHO ENTRE A ILHA DO CAREIRO E A COSTA DO VARRE VENTO

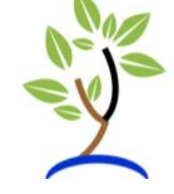

\section{MATERIAIS E MÉTODOS}

O aporte teórico-metodológico que embasou essa pesquisa foi a concepção sistêmica, tendo em vista que a bacia hidrográfica é considerada como um sistema aberto, composto por outros subsistemas, sendo as vertentes, os canais fluviais e as planícies de inundação, os principais subsistemas (NOVO, 2008).

De acordo com Cristofoletti (1979, p.106) os conceitos sistêmicos são subentendidos em toda a análise morfométrica e topológica de redes fluviais, por isso esta concepção é a que melhor se encaixa aos estudos relacionados à geomorfologia fluvial. Além disso, o foco da pesquisa também é compreender a relação da dinâmica fluvial com o transporte de grande calado e consequentemente com os aspectos socioeconômicos.

Para alcançar o objetivo 1, a realização de medições batimétricas, mapeou-se o leito do Rio Amazonas em alguns pontos que compreendem a Costa do Varre Vento. Para a construção dos perfis transversais, serão utilizados os dados fornecidos pelo ecobatímetro digital, da marca Raymarine, modelo L365. A coleta dos dados ocorreu no período de vazante do Rio Amazonas, tendo em vista, que esta é a melhor época para a análise da dinâmica fluvial.

Para atingir o objetivo 2, elaboração de análise espaço-temporal, a ferramenta utilizada foi o sensoriamento remoto, mais especificamente, imagens dos satélites da série Landsat, disponíveis no site do Instituto Nacional de Pesquisas Espaciais INPE. Após a escolha das imagens de melhor qualidade, levando em consideração o período do ano e a cota do rio, foi realizado, na ferramenta Arcgis, o processo de georreferenciamento, seguido do processo de classificação supervisionada e posteriormente sobreposição de imagens, com o intuito de analisar a dinâmica do local.

\section{RESULTADOS E DISCUSSÃO}

O trecho estudado, além de limitar quatro municípios, atua como limite entre formações geológicas, geomorfológicas, apresentando paisagem contrastante nas duas margens (Figura 1). 


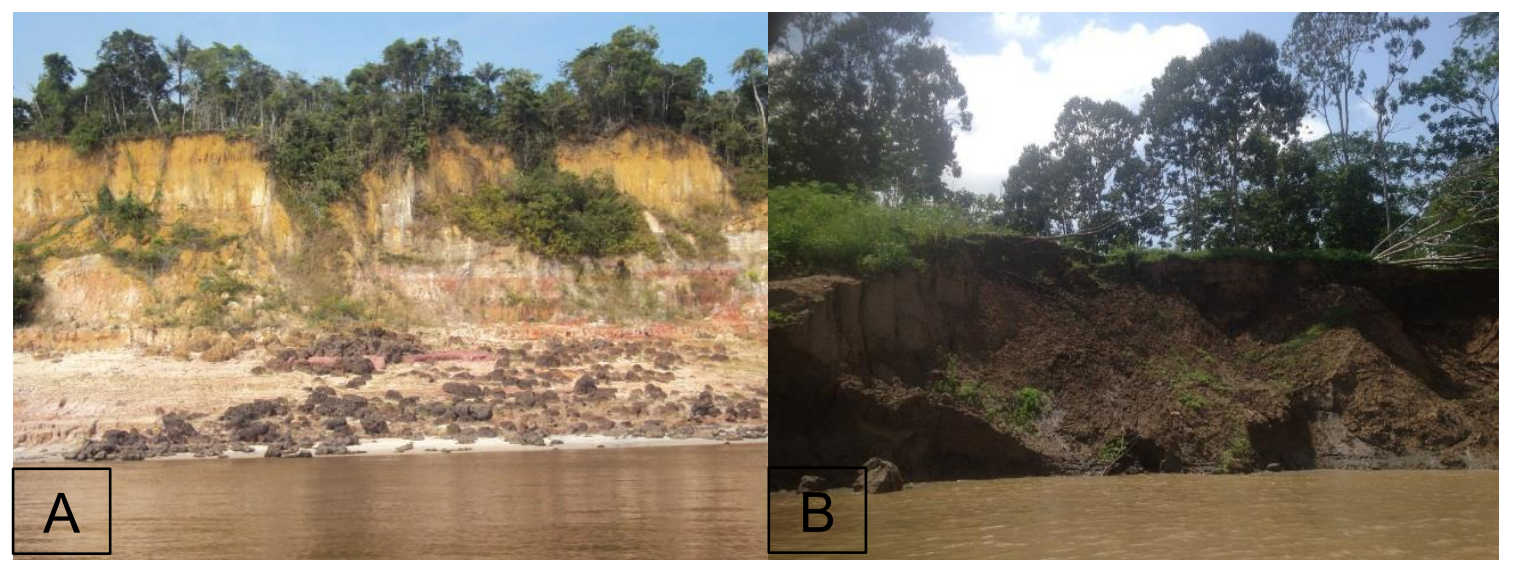

Figura 1: Contraste das margens no trecho da pesquisa. Foto: ARAÚJO, A. G. S. (2017). AMargem esquerda; B- ARAÚJO, A. G. S. (2017). Margem direita.

Em relação à dinâmica fluvial, Sioli (1985), afirma que os rios de água branca, no caso o rio Amazonas, apresentam uma grande quantidade de sedimentos em suspensão, oriundos de intensos processos de erosão nos Andes, local de sua nascente. Logo, neste rio os processos deposicionais são intensos e alteram tanto a paisagem circunvizinha, quanto implicam no transporte fluvial em períodos de vazantes extremas.

Ao realizar análise a partir de sensoriamento remoto, constatou-se a predominância do processo de erosão em relação ao de sedimentação, apesar do surgimento de algumas barras laterais no trecho, poucas alterações são visíveis nessa área.

No entanto, a partir das medições batimétricas dos perfis transversais (Figura 2), foi possível observar que as maiores alterações estão ocorrendo no leito do rio, ou seja, através do processo fluvial denominado de depósito de canal.

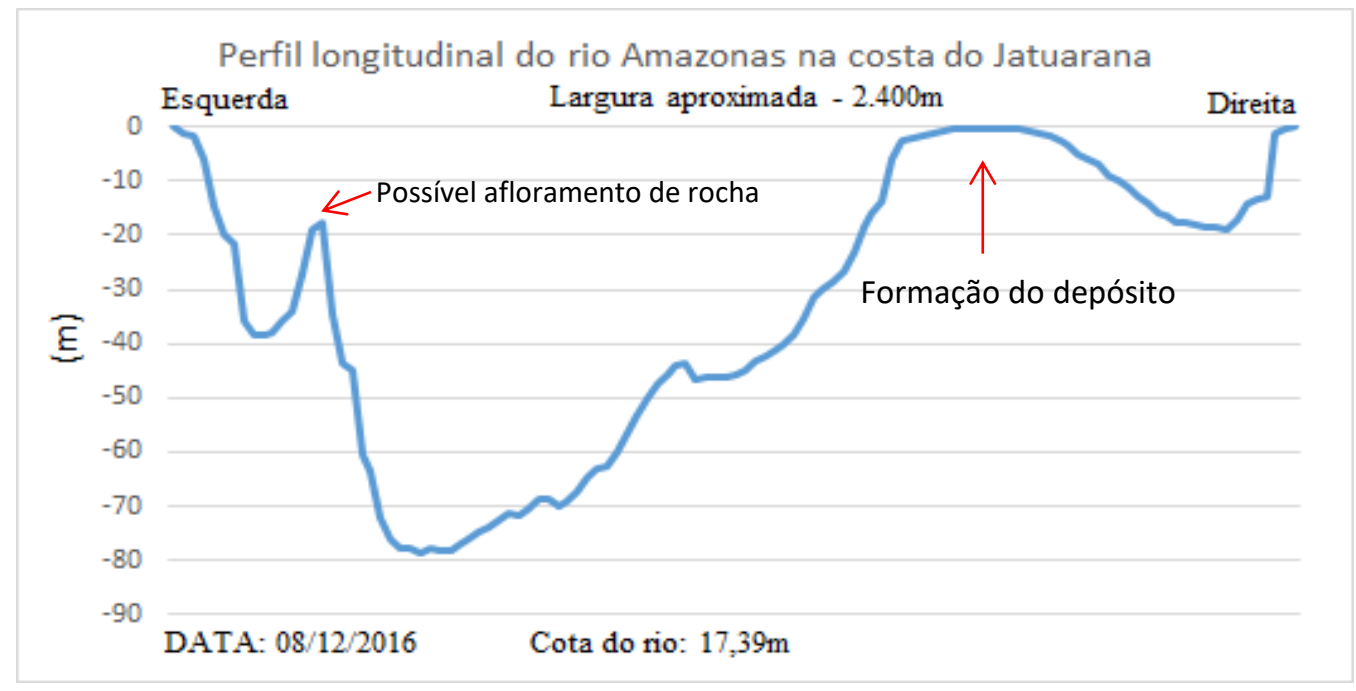

Figura 2. Perfil transversal do rio Amazonas na costa do Jatuarana. Org: ARAÚJO, 2017 
DINÂMICA FLUVIAL DO RIO AMAZONAS NO TRECHO ENTRE A ILHA DO CAREIRO E A COSTA DO VARRE VENTO

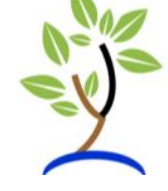

\section{CONCLUSÕES}

Com base nos resultados obtidos, percebe-se uma intensa dinâmica do rio no trecho estudado, principalmente à montante, na llha do Careiro, onde os processos de erosão e deposição são notados de forma mais atuante.

A partir da análise proposta, evidencia-se a intensificação dos processos fluviais ocorrendo na margem direita do rio Amazonas, constituída a partir dos depósitos holocênicos realizados pelo próprio rio. $O$ que contrasta com a análise da margem esquerda, quase que consolidada sobre afloramento de rochas areníticas.

Entretanto, os processos não atuam com exclusividade apenas da llha do Careiro. Os levantamentos batimétricos associados à análise das cartas náuticas da Marinha do Brasil, demonstram que está ocorrendo um intenso processo de sedimentação do leito do rio Amazonas no trecho estudado, o que pode vir a ocasionar implicações em períodos extremos de vazante, quando o nível das águas dos rios fica bem abaixo da média.

Ademais, apesar de fazer parte da dinâmica do rio Amazonas, o processo de deposição fluvial apresenta implicações ao transporte fluvial em períodos de extrema vazante, principalmente para embarcações de grande calado, comprometendo assim a logística e consequentemente a economia e mobilidade da região.

\section{REFERÊNCIAS}

CRISTOFOLETTI, A. A análise de sistemas em Geografia. São Paulo: HUCITEC: Ed. da Universidade de São Paulo, 1979.

NASCIMENTO, D. A; MAURO, C. A; GARCIA, M. G. L. Geomorfologia. Projeto RADAMBRASIL: Folha SA.21-Santarém. Rio de Janeiro: DNPM, 1976. p. 131-198.

ROZO, M. G. Evolução Holocênica do rio Amazonas entre a llha do Careiro e a foz do rio Madeira. Manaus, 2004. (Dissertação).

SIOLI, H. Amazônia - Fundamentos de ecologia da maior região de florestas tropicais. Petrópolis-RJ: Vozes, 1985. 72 p.

SUGUIO, K; BIGARELLA, J.J. Ambientes fluviais. Florianópolis, EDUFSC, 1990.183 p.

Recebido em 13/03/2018

Aceito em 30/05/2018 